\title{
Expression map of entry receptors and infectivity factors for pan-coronaviruses in preimplantation and implantation stage human embryos
}

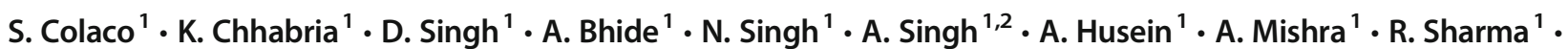 \\ N. Ashary ${ }^{1} \cdot$ D. Modi ${ }^{1}$ (iD
}

Received: 2 December 2020 / Accepted: 8 April 2021 / Published online: 28 April 2021

(C) The Author(s), under exclusive licence to Springer Science+Business Media, LLC, part of Springer Nature 2021

\begin{abstract}
Purpose To predict if developing human embryos are permissive to multiple coronaviruses.

Method We analyzed publicly available single-cell RNA-seq datasets of human embryos for the known canonical and noncanonical receptors and spike protein cleavage enzymes for multiple coronaviruses like SARS-CoV, SARS-CoV-2, MERS-CoV, hCoV-229E, and hCoV-NL63. We also analyzed the expression of host genes involved in viral replication, host proteins involved in viral endosomal sorting complexes required for transport (ESCRT), genes of host proteins that physically interact with proteins of SARS-CoV-2, and the host genes essential for coronavirus infectivity.

Results Of the known receptors of SARS viruses, ACE2, BSG, GOLGA7, and ZDHHC5 were expressed in different proportions in the zygote, 4-cell, 8-cell, morula, and blastocysts including the trophectoderm. The MERS-CoV receptor, DPP4, and hCoV$229 \mathrm{E}$ receptor, ANPEP, were expressed mainly from the compact morula to the blastocyst stages. Transcripts of the MERS-CoV alternate receptor LGALS1 were detected in most cells at all stages of development. TMPRSS2 transcripts were detected in the epiblast, primitive endoderm, and trophectoderm, while transcripts of the endosomal proteases CTSL, CTSB, and FURIN were expressed in most cells at all stages of development. ACE2 and TMPRSS2 were co-expressed in a proportion of epiblast and trophectoderm cells. The embryonic cells expressed genes involved in ESCRT, viral replication, SARS-CoV-2 interactions, and coronavirus infectivity. The ACE2 and TMPRSS2 co-expressing cells were enriched in genes associated with lipid metabolism, lysosome, peroxisome, and oxidative phosphorylation pathways.
\end{abstract}

Conclusion Preimplantation and implantation stage human embryos could be permissive to multiple hCoVs.

Keywords Virus · Coronavirus · SARS-CoV-2 - COVID-19 · ACE2 - TMPRSS2 - Replication · Interaction · In vitro fertilization $\cdot$ scRNAseq

\section{Introduction}

Human coronaviruses (hCoVs) are zoonotic pathogens that cause respiratory tract illnesses ranging from mild common cold to serious virus-associated pneumonia. The seasonal

S. Colaco, K. Chhabria and D. Singh contributed equally to this work.

D. Modi

deepaknmodi@yahoo.com; modid@nirrh.res.in

1 Molecular and Cellular Biology Laboratory, ICMR-National Institute for Research in Reproductive Health, Indian Council of Medical Research (ICMR), JM Street, Parel, Mumbai 400012, India

2 MGM Institute of Health Sciences, MGM Educational Campus, Sector 1, Kamothe, Navi Mumbai 410209, India
hCoVs including hCoV-OC43, hCoV-NL63, and hCoV229E cause mild to moderate upper respiratory tract infections; the Severe Acute Respiratory Syndrome (SARS) family of hCoVs such as SARS-CoV, Middle East Respiratory Syndrome (MERS-CoV), and SARS-CoV-2 are highly pathogenic and cause serious diseases. With multiple spill-over events in recent history, it is clear that the hCoVs have the potential to cross species, spread rapidly, and cause significant morbidity and mortality [1].

Epidemiologic and clinical evidence suggests that pregnant women with hCoV infection are at a higher risk for severe illness and death, as well as adverse pregnancy outcomes, mother-to-child transmission, and congenital viral syndromes [2-6]. While the placenta protects the developing fetus from maternal infections, we and others have shown that the human 
placenta expresses the SARS-CoV-2 receptors and the virus has been detected in placental trophoblasts obtained from infected women, leading to vertical transmission [7-12]. Developmentally, the placenta originates from the cells of the trophectodermal layer of the blastocyst and could be potentially permissive to SARS-CoV-2 infection. Indeed, the SARS receptor, angiotensin-converting enzyme 2 (ACE2), and the viral spike (S) protein priming protease, transmembrane protease serine 2 (TMPRSS2), are expressed in early embryos, mainly in the trophectodermal layer [13-17] while the pseudotyped SARS-CoV-2 virus also enters the cells of the human blastocysts [18]. These observations indicate that human embryos are permissible to SARS-CoV-2 infection.

Considering the spread and pathogenicity of SARS-CoV2 , the current endeavors focused on SARS-CoV-2 are appropriate. However, judging by the rate at which highly virulent coronavirus strains are emerging, we must expand our focus to gain an insight into the permissiveness of human embryos not just to SARS-CoV-2 but other coronaviruses as well. For a complete understanding of the tropism of multiple $\mathrm{hCoVs}$, it is imperative to document the expression profiles of the canonical and non-canonical receptors, co-receptors, and other intracellular factors that are determinants of pan $\mathrm{hCoV}$ infectivity. However, if the human embryos are permissible to other $\mathrm{hCoV}$ infections is still unclear.

ACE2 and TMPRSS2 are the well-established receptor-enzyme pair required for entry of SARS and SARS-CoV-2 and hCoV-NL63 in host cells; MERS, on the other hand, utilizes dipeptidyl peptidase 4 (DPP4) while CoV-229E utilizes aminopeptidase N (ANPEP) as a host receptor [19, 20]. The expression of these receptors in the host cells is a determinant of viral entry. However, it is now apparent that most of the $\mathrm{hCoVs}$ are promiscuous and utilize a plethora of other host proteins that either, independently or synergistically with ACE2, aid in hCoV entry. These include basigin (BSG), neurolipin-1 (NRP1), zinc finger DHHC-type palmitoyltransferase 5 (ZDHHC5), golgin A7 (GOLGA7), and galectin 1 (LGALS1) which interact with the $\mathrm{S}$ protein of coronaviruses and potentially act as the noncanonical mechanism of entry [21-25]. Akin to the receptors, along with TMPRSS2, other members of the TMPRSS family such as the TMPRSS4 and TMPRSS11A aid in S protein priming $[26,27]$. Furthermore, in the endosomal route of hCoV infection, cysteine proteases called cathepsins (CTSL and CTSB) and a paired basic amino acid cleaving enzyme called FURIN process the $\mathrm{S}$ proteins of multiple coronaviruses including that of SARS-CoV-2 [26-29]. The cathepsins and FURIN independently and cooperatively with TMPRSS2 aid in viral entry both in vivo and in vitro [30,31]. However, limited information exists on the expression of such non-canonical factors and other endosomal proteases in human embryos.

For efficient endocytosis, replication, and budding, the $\mathrm{hCoVs}$ use an assortment of intracellular factors that are also considered to be determinants of infectivity. While this information for SARS-CoV-2 and other coronaviruses is beginning to accumulate, studies have identified an array of host proteins that control the infectivity of multiple coronaviruses $[7,25,32,33]$. Whether these factors are expressed in human embryos is currently not known.

In the present study, we developed an expression map of the canonical and non-canonical $\mathrm{hCoV}$ receptors, co-receptors, and the other intracellular factors that are determinants of $\mathrm{hCoV}$ entry, replication, and infectivity in the zygote to lateblastocyst-stage human embryos. We also characterized the molecular signature of the ACE2 and TMPRSS2 coexpressing cells to gain an insight into how the embryos might augment viral infectivity and survival. Our results show that the cells of developing embryos express the necessary machinery to aid in the infectivity of hCoVs. The ACE2 and TMPRSS2 coexpressing cells of the embryos are enriched for genes in metabolic pathways that promote viral survival and replication.

\section{Materials and methods}

To determine the mRNA levels of the factors that are determinants of hCoV entry, two single-cell RNA-Seq (scRNAseq) datasets [34, 35] were analyzed. The dataset by Stirparo et al. 2018 was chosen as it contained uniformly analyzed samples from three published studies [35-37] and recapitulated the known lineage markers of the zygote to late blastocysts. It also allowed an in-depth exploration of the transcriptome of multiple cells in the inner cell mass (ICM), epiblast and primitive endoderm. The dataset from Petropoulos et al. 2016 (accession number: E-MTAB-3929) was chosen as it permitted exploration of a large number of trophectoderm cells from day 5 to day 7 blastocysts. Supplementary Table 1 gives the number of embryos and the total number of cells analyzed in this study.

The host receptors utilized by various hCoVs were identified by systematic literature review and the list is given in Table 1. The genes encoding protein products involved in the endosomal sorting complex required for transport

Table 1 Summary of host receptors of coronaviruses that infect humans

\begin{tabular}{ll}
\hline Receptor & Viral tropism \\
\hline ACE2 & SARS-CoV-2, SARS-CoV, hCoV-NL63 \\
ANPEP & hCoV-229E \\
BSG & SARS-CoV-2, SARS-CoV \\
DPP4 & MERS-CoV \\
GOLGA7 & SARS-CoV-2, SARS-CoV \\
LGALS1 & MERS-CoV \\
NRP1 & SARS-CoV-2, SARS-CoV \\
ZDHHC5 & SARS-CoV-2, SARS-CoV \\
\hline
\end{tabular}


(ESCRT) and SARS virus replication in host cells were obtained [32,38] and the list provided in Supplementary Tables 2 and 3 respectively. The mRNA levels of 332 human proteins that physically interact with proteins of SARS-CoV-2 [33] are listed in Supplementary Table 4. The expression of 67 host genes that are essential for infectivity of multiple coronaviruses [25] is given in Supplementary Table 5.

The mRNA levels of selected factors in individual cells of embryos at each stage of development were extracted from the datasets. Psuedo-bulk analysis was carried out for each gene as described before [9]. To define the gene signatures of ACE2+ TMPRSS2+ cells, pseudo-bulk analysis of single-cell data of the epiblast and trophectoderm cells of day 7 blastocyst was carried out. The epiblast and day 7 trophectoderm were chosen as they had a reasonable proportion of cells co-expressing ACE2+TMPRSS2+ versus those that did not express either. This allowed us to have enough cells in both groups to reasonably apply statistical testing. For pseudo-bulk analysis, the mean values of all the genes expressed in the ACE2 and TMPRSS2 co-expressing cells (ACE2+TMPRSS2+) and ACE2 and TMPRSS2 negative cells (ACE2-TMPRSS2-) were computed. Genes that had a ratio of $\geq 1.5$ or $\leq 0.5$ with a significantly different mean value $(p \leq \overline{0} .05)$ using Welch's $t$ test were filtered as described previously [9].

To assess the permissiveness of human embryos to different $\mathrm{hCoVs}$, we noted the expression of the canonical receptors along with TMPRSS2. Those embryonic stages which co-expressed the canonical receptor along with TMPRSS2 were considered permissive to hCoVs. Besides, we scored the embryonic stages for the percentage of expressed genes in ESCRT, viral replication, and SARS-CoV-2 infectivity. When 1-10\% of the total genes for the above processes were expressed in the embryos, a score of + 1 was assigned, a score of +2 was assigned when $11-50 \%$ of genes were expressed, and a score of +3 was assigned when $>$ $50 \%$ of genes were expressed.

The Gene Ontologies (GO) were obtained using gProfiler (https://biit.cs.ut.ee/gprofiler/gost). Categories enriched with Benjamini-Hochberg False Discovery Rate $[$ FDR $]<0.05$ were considered. Pseudo-bulk and deconvoluted single-cell data were visualized using Morpheus (https://software. broadinstitute.org/morpheus) and R Studio version 3.6.2 with the Seurat and ggplot2 packages (RStudio Team, Boston, MA http://www.rstudio.com/). Figure 6 was created using BioRender (https://biorender.com/).

\section{Results}

\section{Embryos express receptors and S protein processing enzymes for multiple coronaviruses}

Of the SARS receptors, ACE2 was abundantly present in the zygotes after which its level progressively reduced until the compact morula stage. The numbers of cells and the transcript levels of ACE2 increased in the ICM and again reduced in the epiblast and primitive endoderm. Transcripts for $B S G, Z D H H C 5$, and GOLGA7 were detected in most cells of the developing embryo. NRP1 mRNA was detected primarily in a proportion of cells of the epiblast and primitive endoderm with little or no expression in the cells at other developing stages (Fig. 1).
Fig. 1 mRNA expression of coronavirus receptors and spike protein processing enzymes in human embryos. Bubble plots showing relative expression and proportion of cells expressing ACE2 (receptors for SARS-CoV, SARS-CoV-2, and CoV-NL63), $B S G, N R P 1, Z D H H C 5$ and GOLGA7 (SARS-CoV, SARSCoV-2 alternate receptors), $D P P 4$ and $L G A L S 1$ (receptor/interacting partners of MERS-CoV), and ANPEP (receptors for hCoV229E). scRNAseq data for embryonic cells was obtained from [34] while that of trophectodermal cells on different days of embryonic development was obtained from [35]
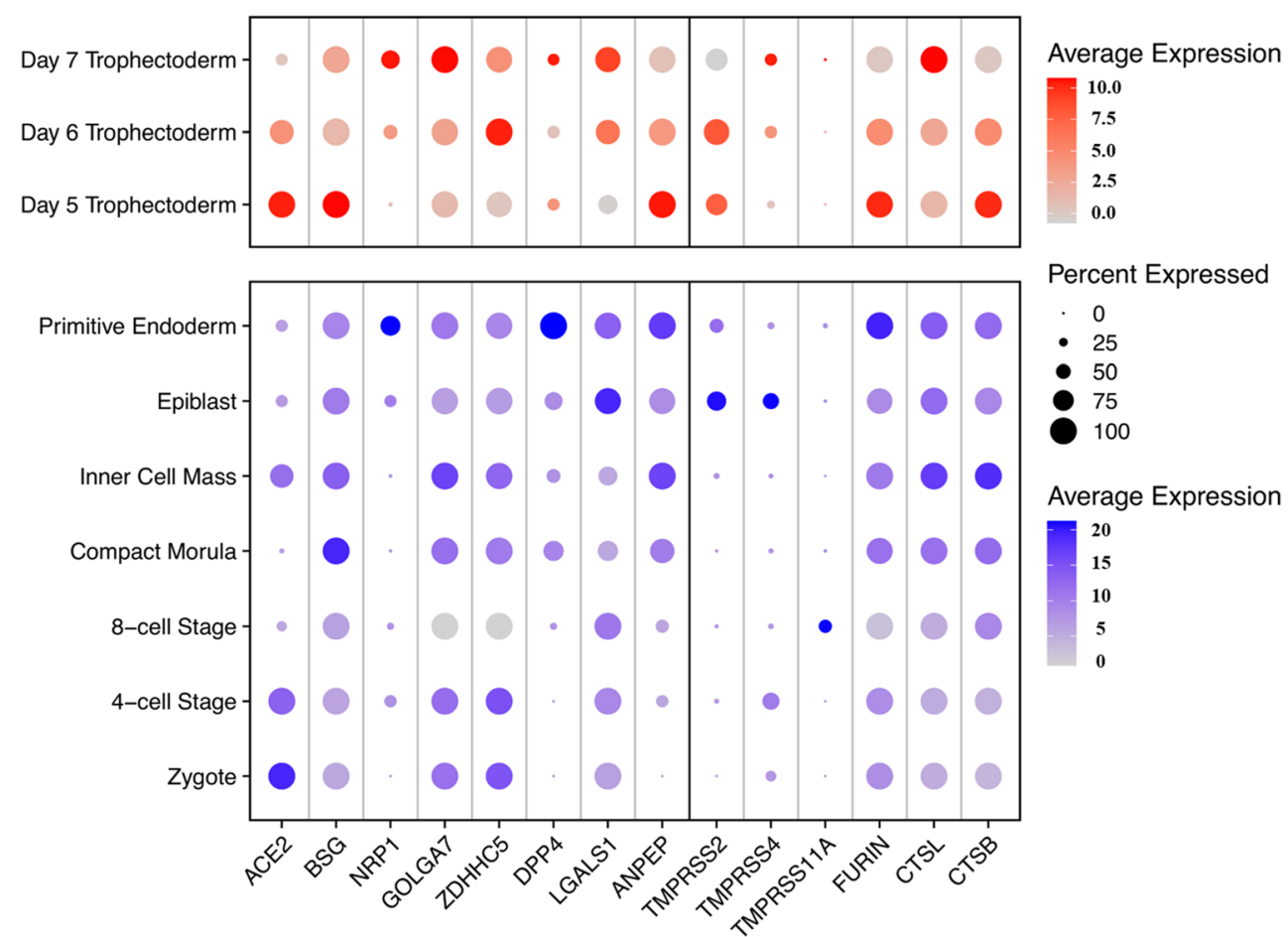
DPP4 (the MERS-CoV receptor) mRNA was detected in a proportion of cells of the compact morula and the expression was highest in the primitive endoderm. LGALS1 is a MERS S protein-interacting partner and its transcripts were detected in most cells of the embryos at all stages (Fig. 1).

ANPEP (the hCoV-229E receptor) transcripts were present in low abundance in the zygote to 8-cell stage embryos. The transcript levels increased in the compact morula, ICM, epiblast, and the primitive endoderm (Fig. 1).

TMPRSS2 mRNA was detected in a proportion of cells of the epiblast and primitive endoderm, while TMPRSS4 transcripts were detected in the zygote, 4-cell stage, and the epiblast. TMPRSS11A was expressed weakly only in the 8-cell embryo (Fig. 1). FURIN, CTSL, and CTSB transcripts were detected in most of the cells of the developing embryos at all stages (Fig. 1).

\section{Dynamic changes in expression of coronavirus receptors and $S$ protein processing enzymes in the trophectoderm}

High levels of ACE2 mRNA were detected in most trophectoderm cells of the day 5 and 6 blastocysts which were reduced on day 7. BSG, GOLGA7, and ZDHHC5 mRNA was expressed in all the cells of the trophectoderm of day 5-7 blastocysts (Fig. 1). NRP1 on the other hand was expressed only in a subset of trophectoderm cells of day 6 blastocysts which increased on day 7 .

a
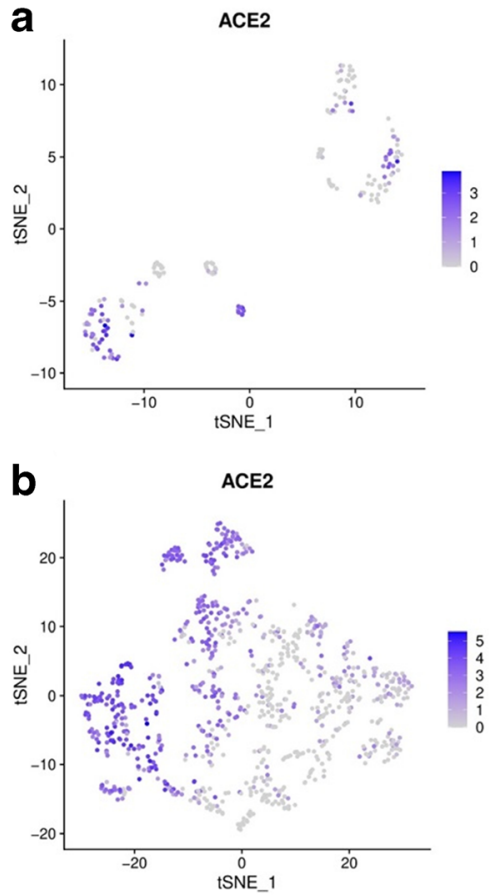
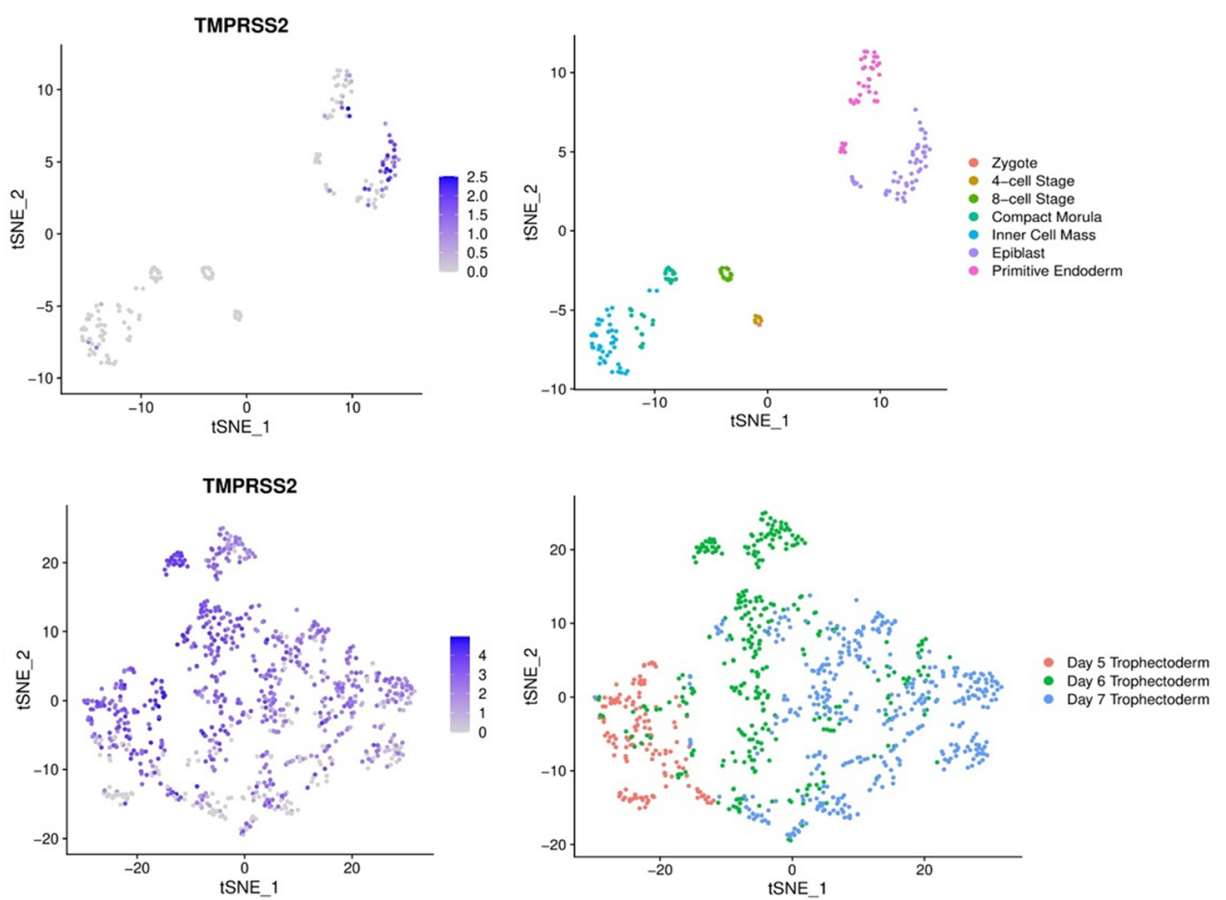

Fig. 2 ACE2 and TMPRSS2 expressing cells in the developing human embryos. tSNE plots for ACE2 and TMPRSS2 in cells of the developing embryos (a) and trophectoderm of day 5-7 blastocysts (b). Data was obtained from scRNAseq of developing human embryos [34, 35] 
epiblast co-expressed both these genes (Fig. 2, Supplementary Table 1).

In the trophectodermal lineage, $77 \%$ of day 5 blastocysts and $83 \%$ of day 6 blastocysts co-expressed ACE2 and TMPRSS2. The numbers of ACE2 and TMPRSS2 coexpressing trophectoderm cells of the day 7 blastocyst declined to $33 \%$ (Fig. 2, Supplementary Table 1).

\section{mRNA levels of proteins involved in viral endocytosis, replication, and SARS-CoV-2 interaction}

We analyzed mRNA levels of the genes involved in ESCRT for viruses. Pseudo-bulk analysis revealed that very few ESCRT genes were expressed from the zygote to the 8-cell stage. The expression levels of these genes dramatically increased in the ICM, epiblast, primitive endoderm, and trophectoderm of day 5-7 blastocysts (Fig. 3, Supplementary Table 2).

Pseudo-bulk analysis revealed that mRNA of host genes involved in coronavirus replication were barely expressed in the zygote, 4- and 8-cell stages. Their levels surged in the compact morula, ICM, epiblast, and the primitive endoderm. Expression of most of these genes was observed in the trophectoderm cells of day 5-7 blastocysts (Fig. 3, Supplementary Table 3).
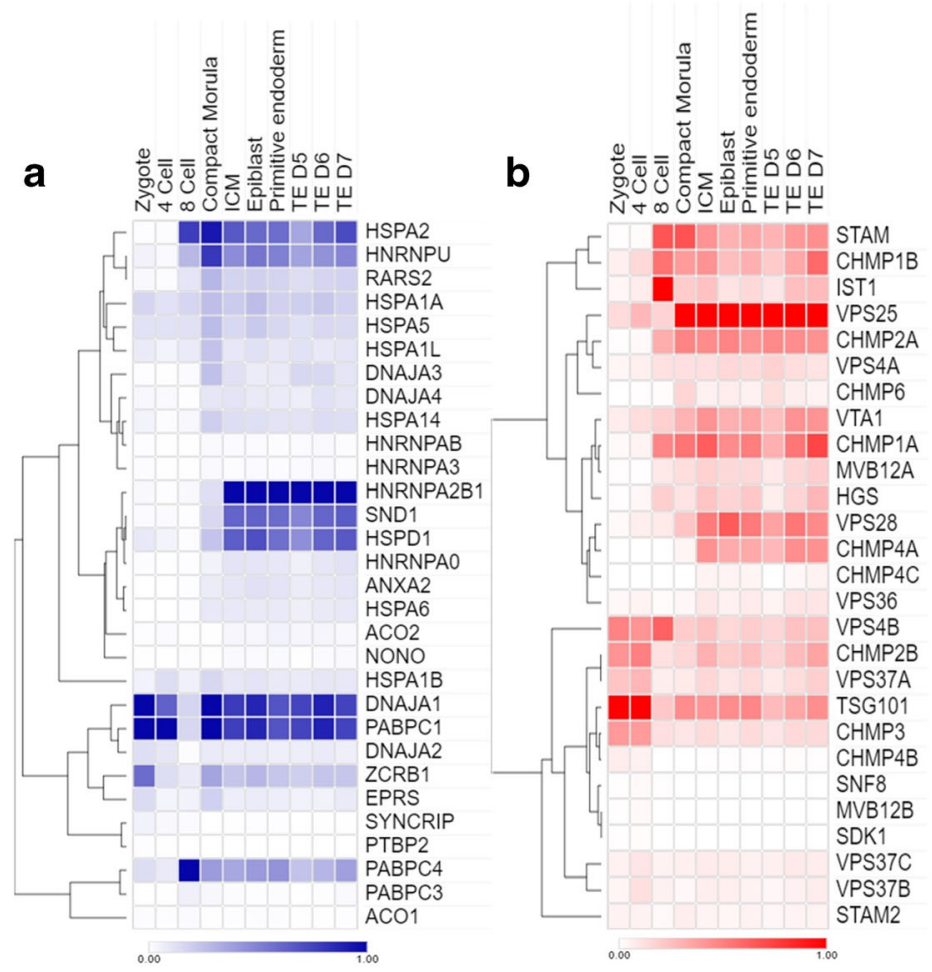

Fig. 3 mRNA levels of genes involved in endosomal complexes required for transport (ESCRT), viral replication, host-SARS-CoV-2 proteinprotein interactions, and essential genes involved in coronavirus infectivity in human embryos. Pseudo-bulk data for the mRNA levels of genes involved in (a) ESCRT, (b) viral replication, (c) SARS-CoV-2
SARS-CoV-2 proteins interact with 332 proteins in human cells. As evident by pseudo-bulk analysis, only few of these genes were expressed in the zygote and 4-cell stage embryos. Their levels increased from the 8-cell stage onwards until the blastocyst stage. Most of these genes were also expressed in the trophectoderm of day 5-7 blastocysts (Fig. 3, Supplementary Table 4).

At single-cell resolution, the mRNA levels of proteins involved in ESCRT, viral replication, and SARS-CoV-2 interaction were found to have minimal heterogeneity in most cells of the epiblast and the trophectoderm, irrespective of their $A C E 2$ and TMPRSS2 status (Supplementary Fig. 1).

\section{Host genes essential for coronaviruses infectivity are expressed in the developing embryos}

We next studied the mRNA levels of 67 host proteins that are experimentally shown to interact with proteins of multiple coronaviruses and are necessary for SARS-CoV-2 replication. Pseudo-bulk analysis revealed that most of these genes were expressed in low abundance in the cells of the zygote, 4- and 8-cell embryos. However, their expression increased in the compact morula, ICM, epiblast, primitive endoderm, and the trophectoderm (Fig. 3, Supplementary Table 5).

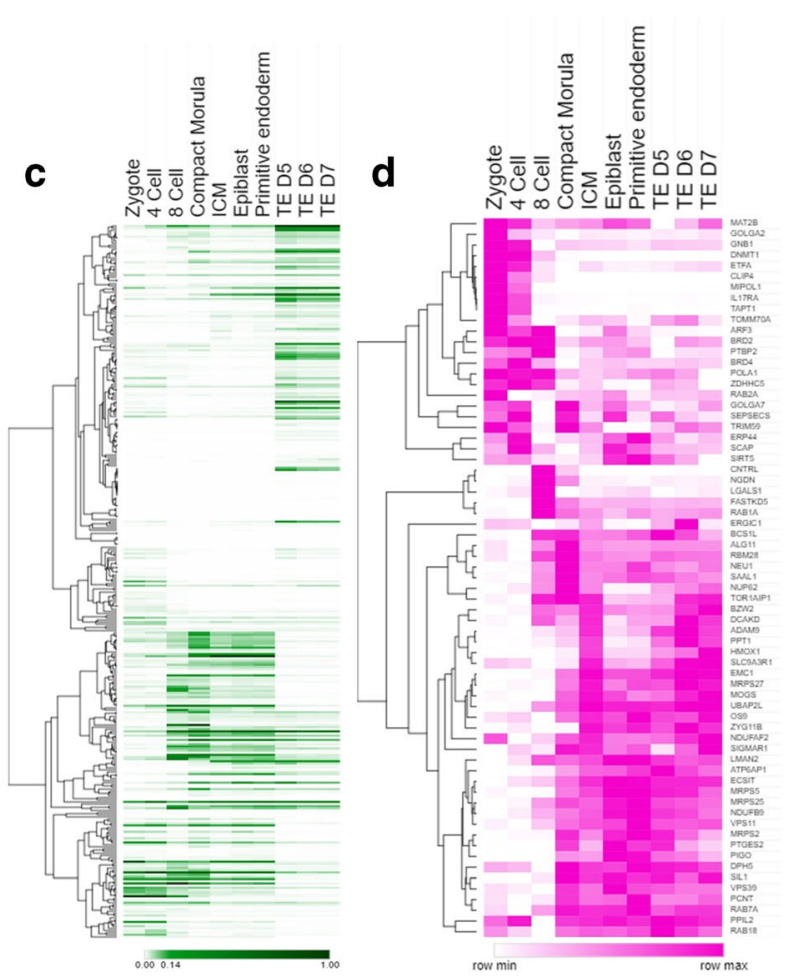

interactions, and (d) coronavirus infectivity. All data were extracted from scRNAseq of developing human embryos [34] and from trophectoderm cells from [35]. In all heat maps, each row depicts a gene and each column depicts a stage of embryonic development. Data is presented in the relative color scale 

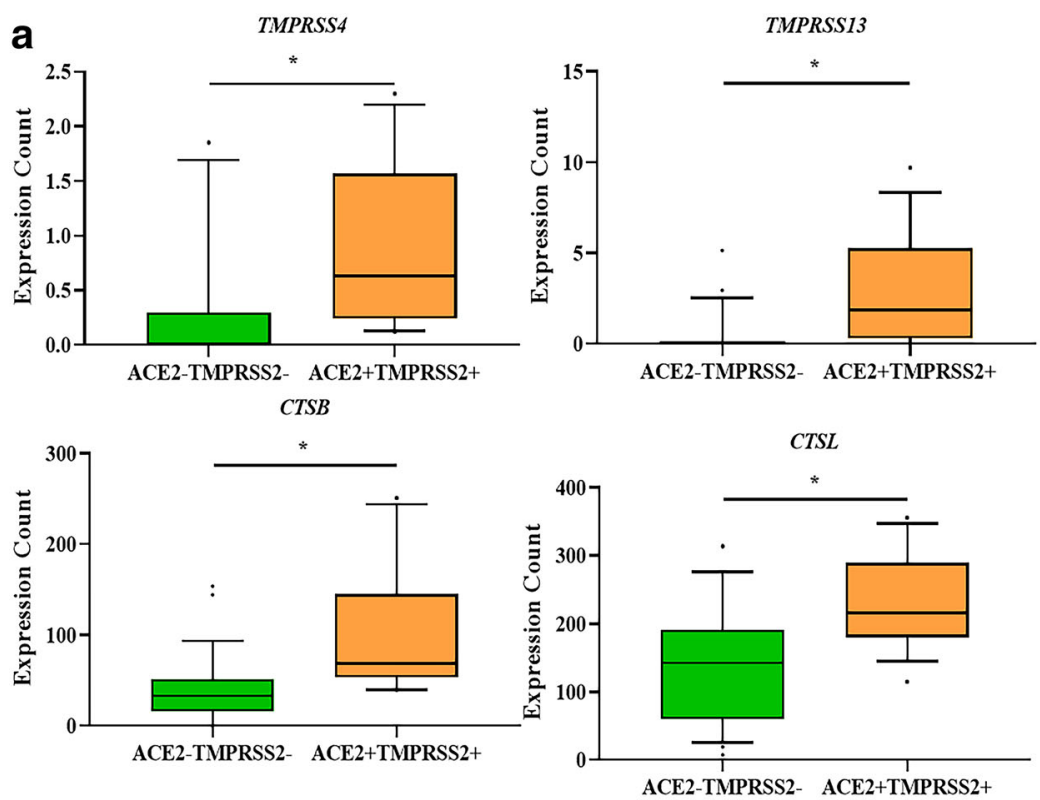

b
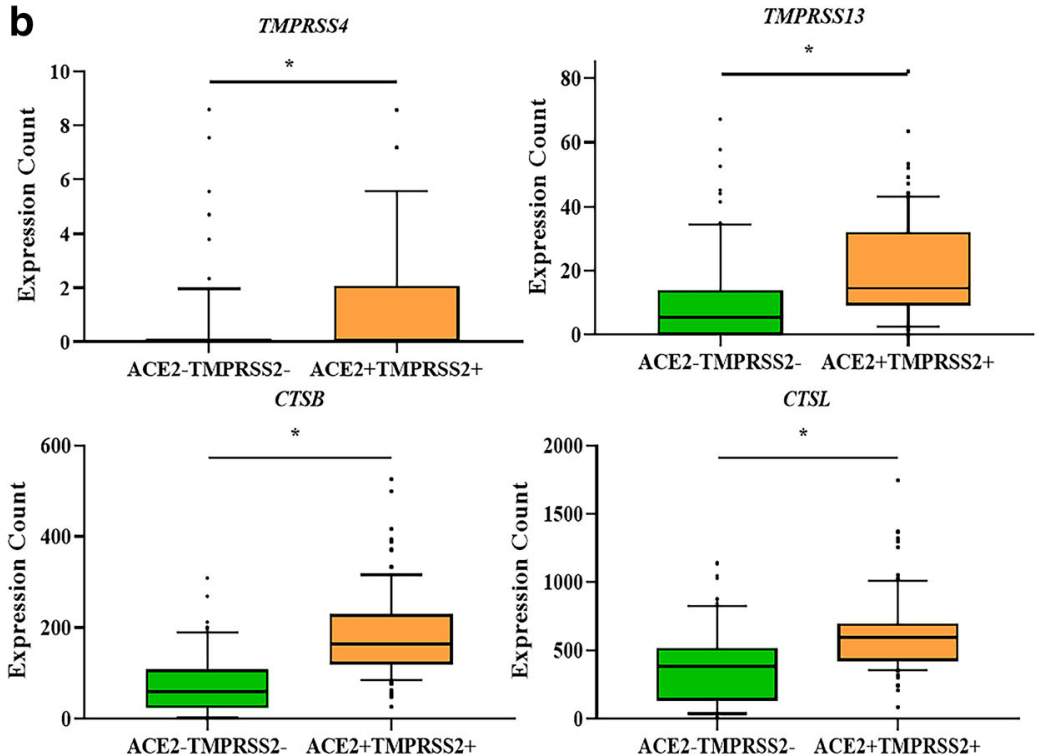

C

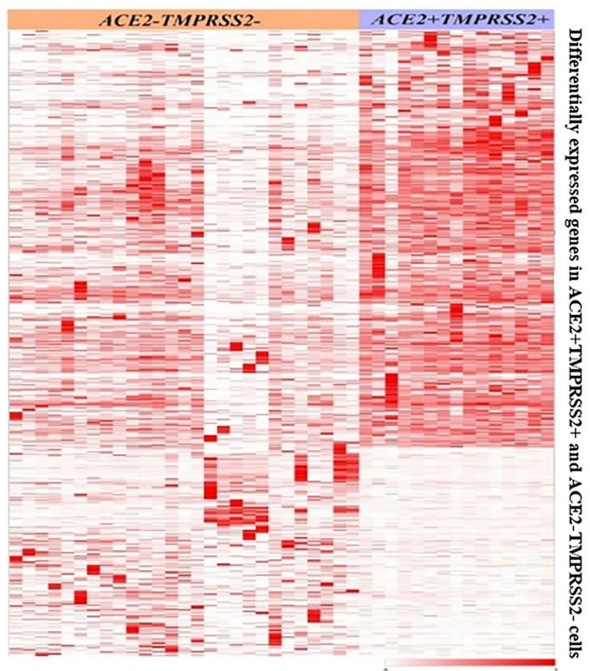

d

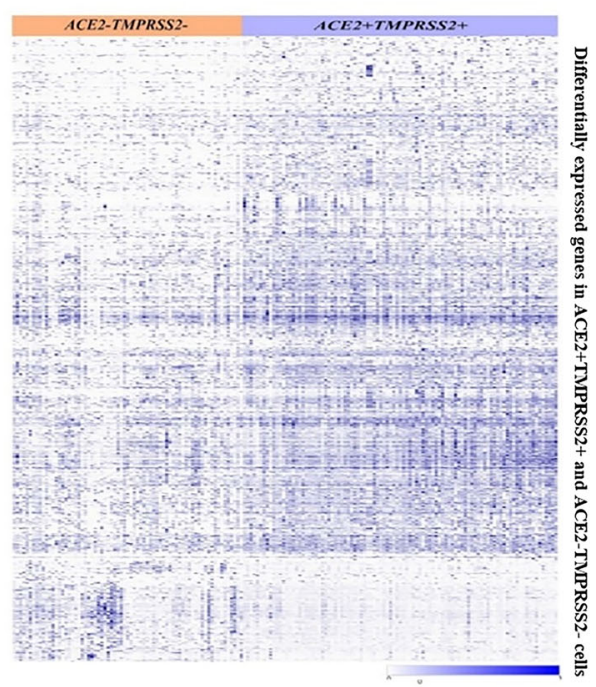

Fig. 4 Differentially expressed genes in ACE2 and TMPRSS2 coexpressing cells in epiblast and trophectoderm cells. a Expression of TMPRSS4, TMPRSS13, CTSB, and CTSL in ACE2-TMPRSS2- and $A C E 2+T M P R S S 2+$ cells of epiblast. b Expression of TMPRSS4, TMPRSS13, CTSB and CTSL in ACE2-TMPRSS2- and ACE2+ TMPRSS2 + cells of trophectoderm. Significantly different $(p<0.05)$ mean values are marked as *. c Heat map of the distribution of differentially expressed 1985 genes in ACE2- and TMPRSS2-negative (ACE2-
TMPRSS2-) and ACE2 and TMPRSS2 co-expressing (ACE2+ TMPRSS2+) cells of the epiblast. d Heat map of the distribution of 1453 differentially expressed genes in ACE2-TMPRSS2 - and ACE2+ TMPRSS2 + trophectoderm cells. In $\mathbf{c}$ and $\mathbf{d}$, rows represent genes and columns represent individual cells, presented on a relative color scale. Data were extracted from scRNAseq of the epiblast of developing human embryos [34]; trophectoderm data was extracted from [35]

\section{ACE2 and TMPRSS2 co-expressing cells of the epiblast and trophectoderm are enriched for genes that aid in viral pathogenesis}

In the epiblast and trophectoderm, the ACE2 and TMPRSS 2 co-expressing cells (ACE2+TMPRSS2+ cells) were enriched for several S protein cleavage enzymes (Fig. 4). In the ACE2+ TMPRSS2+ cells of the epiblast and day 7 trophectoderm,
TMPRSS4, TMPRSS13, CTSB, and CTSL transcripts were significantly overexpressed as compared to the cells not coexpressing both these genes ( $p$-value $\leq 0.05)$. Other members of the TMPRSS and Cathepsin family were also enriched in the ACE2+TMPRSS2+ cells, although they did not reach statistical significance (Supplementary Fig. 2).

We identified 1985 genes that were differentially expressed between the ACE2+TMPRSS2+ and ACE2-TMPRSS2- cells 
of the epiblast (Fig. 4, Supplementary Table 6). Of 1985 differentially expressed genes in the epiblast, nearly $67 \%$ of genes were overexpressed in the ACE2+TMPRSS2+ cells as compared to ACE2-TMPRSS2 - cells. The majority of these genes were uniformly expressed in the ACE2 and TMPRSS2 co-expressing cells but their expression was highly heterogeneous in the ACE2-TMPRSS2- cells (Fig. 4).

In the trophectodermal lineage, pseudo-bulk analysis identified 1453 differentially expressed genes between ACE2+ TMPRSS2+ and ACE2-TMPRSS2- cells (Fig. 4, Supplementary Table 7). Of these, $83.5 \%$ were overexpressed in the ACE2+TMPRSS2+ cells as compared to ACE2TMPRSS2 - trophectoderm cells (Supplementary Table 7).

Comparative analysis of the differentially expressed transcripts identified 216 genes that were common in both the epiblast and day 7 trophectodermal lineage; 1768 genes were unique to the epiblast, while 1236 genes were unique to the trophectoderm (Fig. 5, Supplementary Table 8). The biological processes associated with the 216 common genes were steroid metabolism and biosynthesis of sterol, alcohol, and cholesterol. The enriched Kyoto Encyclopedia of Genes and
Genomes (KEGG) pathways included lysosome and steroid biosynthesis (Fig. 5). The biological processes associated with genes unique to epiblast cells were associated with embryonic development, small molecule and energy metabolism, and cholesterol biosynthesis. The enriched KEGG pathways were oxidative phosphorylation and metabolic pathways (Fig. 5). The biological processes associated with the genes unique to the trophectoderm were associated with glycolipid metabolism, lipopolysaccharide metabolism, and leukocyte activation. The KEGG pathways associated with these genes were lysosome, peroxisome, glycan degradation, and herpes simplex virus infection (Fig. 5).

Our results show that different stages of the developing human embryos may be permissive to multiple hCoVs (Fig. 6). Based on the expression map of ACE2, ANPEP, and DPP4 along with TMPRSS2, the early stages (zygote until 8-cell stage) may not be permissive to hCoVs as they lack TMPRSS2. However, the cells of these stages do express the alternate receptors and abundant amounts of endosomal proteases. The zygote and 4-cell stage embryos express almost $10 \%$ of genes involved in viral endocytosis, replication, and
Fig. 5 Biological processes enriched in ACE2 and TMPRSS2 co-expressing epiblast and trophectoderm cells. Venn diagram showing numbers of differentially abundant genes unique and common in ACE2 and TMPRSS2 co-expressing day 7 trophectoderm (D7 TE) cells and epiblast cells. The hatched bar are terms of the KEGG pathways, the solid bars represent the biological processes. Values on $\mathrm{X}$-axis are $\log 10$ adjusted $p$-value. Data were obtained from scRNAseq of the epiblast [34] and trophectoderm cells of day 7 blastocyst [35]

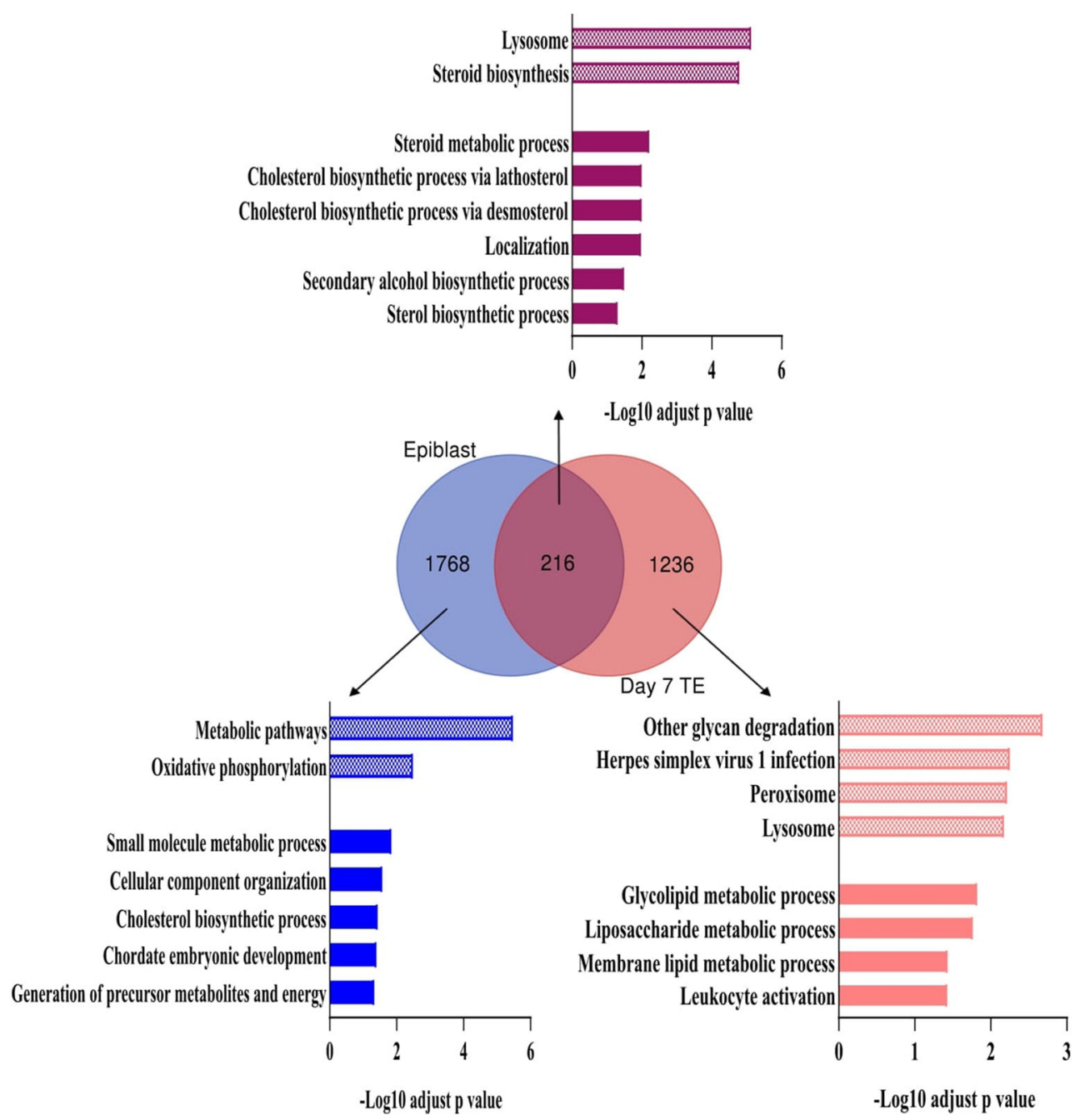


Fig. 6 Permissiveness of human embryos to multiple coronaviruses. Different colors represent different cell types in the blastocyst stage. Blue, green, and yellow cells represent trophectoderm, epiblast, and primitive endoderm respectively. The permissiveness of human embryos to different coronavirus was estimated based on the presence of the mRNA for canonical receptors ( $A C E 2$, $D P P 4$, and $A N P E P$ ) and TMPRSS2 and the numbers of expressed genes involved in viral ESCRT, viral replication, and viral infectivity. If $1-10 \%$ of the total genes for the above processes were expressed in the embryos, a score of +1 was assigned, a score of +2 was assigned when $11-50 \%$ of genes were expressed, and a score of +3 was assigned when $>50 \%$ of genes were expressed

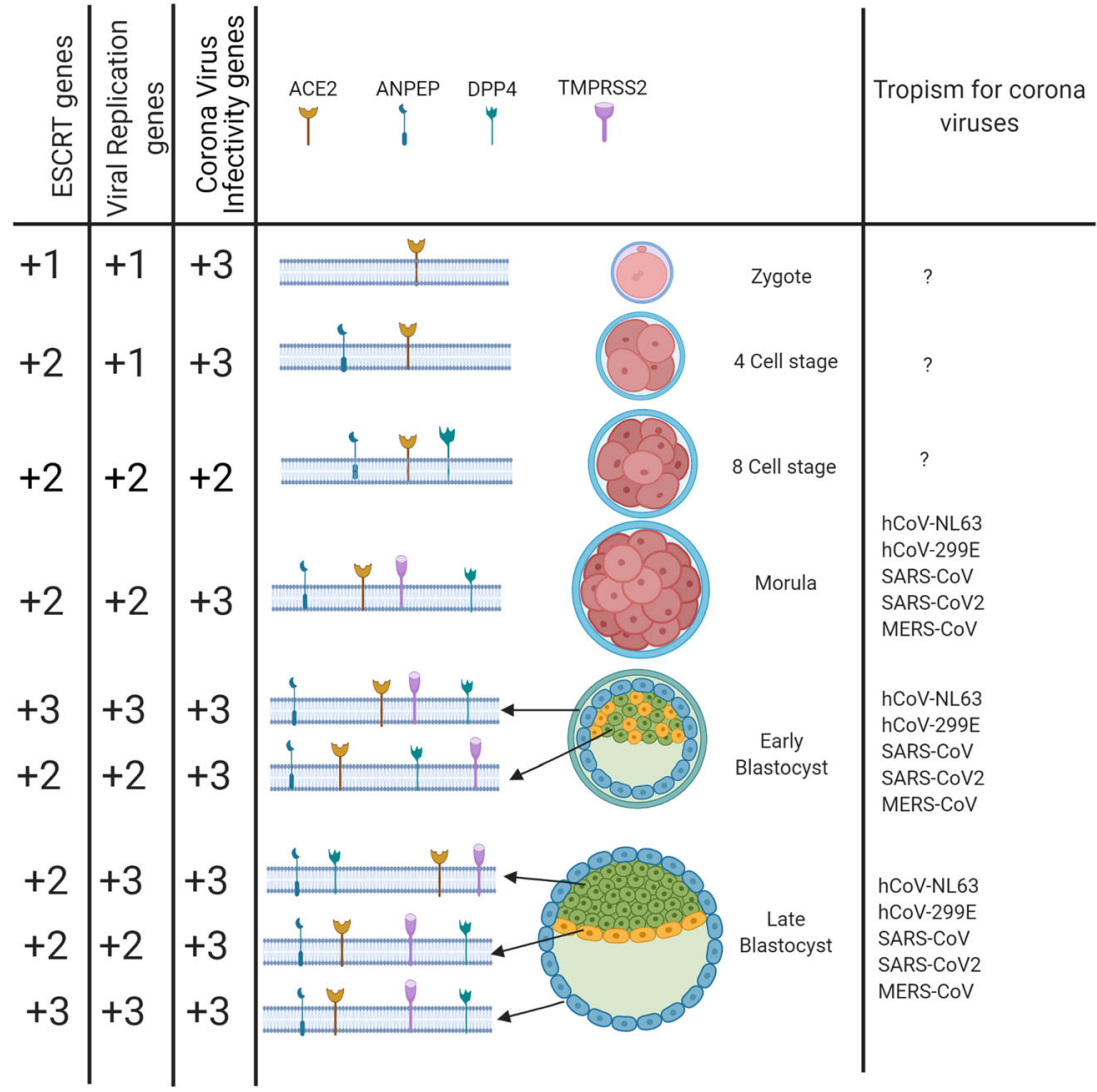

coronavirus infectivity. From the 8-cell stage onwards, the cells of the embryos consistently express receptors for multiple hCoVs and most of the genes involved in ESCRT, viral replication, and SARS infectivity. The trophectoderm cells are most enriched for mRNA of the receptors, ESCRT, viral replication, and coronavirus infectivity-related proteins.

\section{Discussion}

The results of the present study demonstrate that the developing preimplantation and implantation stage human embryos dynamically express the mRNA of receptors and the $\mathrm{S}$ protein processing enzymes for multiple coronaviruses. They also express the factors that aid in endocytosis, replication, and infectivity of multiple hCoVs.

The pandemic of SARS-CoV-2 causing COVID-19 has drawn tremendous attention of researchers globally and it is now clear that COVID-19 during pregnancy is associated with multiple adverse outcomes including mother-to-child transmission $[3,4,6,8,10]$. Considering the high rate of human-tohuman transmission and viral shedding from both symptomatic and asymptomatic individuals [39], high asymptomatic to symptomatic patient ratio [40] and ability of the viruses to survive on inanimate objects for extended periods and at sub-zero temperatures [41, 42], the clinics offering assisted reproduction services are at risk of spreading COVID-19 [43]. With the resumption of services for assisted reproduction in many parts of the world [44, 45], the clinics must be aware of the risks that the virus poses on gametes and early embryos. Indeed, we and others have demonstrated that ACE2 is expressed in the different types of embryonic and trophectodermal cells [14-18]. Herein, we observed that nearly $12 \%$ of ICM, $16 \%$ of primitive endoderm, $41 \%$ of the epiblast cells, and $70-80 \%$ of the trophectodermal cells (of day 5-6 blastocysts) and 33\% of day 7 blastocysts co-expressed both ACE2 and TMPRSS2. These numbers are comparable to those reported in previous studies that analyzed ACE2 and TMPRSS2 co-expressing cells in human embryos using different scRNAseq datasets $[14,16]$. These results reflect the robustness of our analysis and further reinforce the notion that human embryos could be permissive to SARS-CoV-2.

Considering the severity and urgency of the COVID-19 pandemic, the current endeavors focused on SARS-CoV-2 are appropriate. However, due to the high frequency at which virulent coronavirus strains emerge, there is a need to identify the tropism of multiple hCoVs to human embryos. Towards this, we profiled the cells of the developing human embryos for expression of the canonical and non-canonical receptors and $\mathrm{S}$ protein cleavage enzymes for multiple hCoVs. Our results show that the canonical SARS receptor ACE2 is expressed from the zygote to blastocyst stages. The MERS 
receptor DPP4 and the hCoV-299E receptor ANPEP are expressed from the compact morula stage and continue its expression in a proportion of ICM and the trophectoderm. Interestingly, the cells of the epiblast and primitive endoderm also express mRNA for the $\mathrm{S}$ protein cleavage enzyme TMPRSS2. Besides, a proportion of the ACE2, ANPEP and DPP4 expressing cells co-express TMPRSS2 (data not shown) indicating that the canonical mode for multiple hCoVs entry exist in the morula and blastocysts. Intriguingly, the ACE2 and TMPRSS 2 co-expressing cells are enriched for the mRNA of several members of TMPRSS and cathepsin family of proteases that aid in $\mathrm{S}$ protein processing of different $\mathrm{hCoVs}$ that may potentiate infectivity. Along with the canonical receptors, many cells of developing human embryos right from the zygotic stages express the mRNA for the noncanonical hCoV entry receptors $B S G, Z D H H C 5, G O L G A 7$ and LGALS1. These results imply that the human preimplantation and implantation stage embryos could be permissive to multiple hCoVs through both the canonical and non-canonical entry routes.

Along with ACE2-TMPRSS2-facilitated entry, many hCoVs can also enter the host cells via the endosomal route $[28,29,46]$. Intriguingly, some coronaviruses like the HCoV229E, HCoV-OC43, and hCoV-HKU1 prefer the endosomal mode of entry over receptor-mediated pathways [29]. In the endosomal mode, the spike proteins need to be proteolytically activated, which is achieved by CTSL, CSTB, and FURIN $[28,29]$. These enzymes cooperatively and independently promote SARS-CoV-2 entry in host cells both in vitro and in vivo [29-31]. Herein, we observed that all these three enzymes are expressed in most cells of the preimplantation and implantation stage embryos including the trophectoderm. Interestingly, the cells of the embryos are also enriched for other cathepsin family members implying that along with receptor-mediated entry, the endosomal mechanisms are operative and may also potentiate viral entry in embryonic cells. Indeed, a neutralizing antibody against ACE2 reduced but did not completely abolish reporter signals in the trophectoderm of human blastocyst challenged with pseudotyped SARSCoV and SARS-CoV-2 [18]. These results indicate that human embryos could be permissible to multiple coronaviruses by both receptor and non-receptor mediated pathways.

Once the virus binds to the receptor and the S protein undergoes priming, most enveloped viruses recruit the ESCRT machinery of the host cell for endocytosis [32]. Current evidence suggests proteins of $\mathrm{hCoVs}$ also interact with members of the ESCRT pathway and blocking some of these hinders their replication $[7,25,33]$. Interestingly, we observed that the transcripts of proteins involved in ESCRT are expressed in the zygote and 4-cell embryos; a surge in the expression of these genes occurs in the 8-cell stage onwards. Notably, these genes were expressed in most cells irrespective of their $A C E 2$ status. Given the fact that the coronavirus can also enter the cells by the endosomal route, the abundance of ESCRT genes may facilitate the entry of hCoVs in the early stages of human embryos even in absence of the ACE2-TMPRSS2 facilitated entry machinery.

Once the virus enters the cells, the next step in the infectious cycle is replication, which involves a distinct set of host proteins $[25,38]$. Our results reveal that as compared to the earlier stages, the cells of the compact morula show a surge in mRNA expression of most host proteins involved in viral replication. Notably, at the single-cell resolution, we observed that irrespective of whether the cells expressed the necessary receptors and the proteases, the genes of the ESCRT and the viral replication pathways are expressed in most cells of the blastocysts. These results indicate that the human blastocysts not only have the necessary machinery for viral attachment and entry but also readily express the infrastructure to facilitate viral replication.

Inside the host cells, coronaviruses translate proteins that physically interact with a plethora of host proteins. These host proteins have roles in a wide range of cellular functions including DNA replication, lipid modification, RNA processing, cytoskeletal organization, and mitochondrial functions [33]. We observed that mRNA for SARS-CoV-2 interacting proteins are expressed in most cells from the 8-cell stage embryos and onwards. Notably, within this human and SARS$\mathrm{CoV}-2$ protein interactome, there are 67 proteins that also interact with proteins of other hCoVs. Further, depleting these 67 proteins individually causes a significant reduction in SARS-CoV-2 replication in human cells [25]. We observed that the mRNA of the 67 coronavirus infectivity-related genes are abundantly expressed in the cells of the developing embryos specifically from the compact morula stage onwards. Taken together, our analysis provides evidence for the presence of the regulatory hubs involved in coronavirus infectivity in preimplantation and implantation stage human embryos.

To understand how the cells of the embryos augment viral infectivity and survival, we scanned the cells of the epiblast and trophectoderm that co-express ACE2 and TMPRSS2. The results revealed that the ACE2 and TMPRSS2 co-expressing cells of the epiblast and trophectoderm are enriched for genes involved in lipid metabolism. Host cell fatty acid synthesis machinery is known to aid in viral replication and to shield the viral nucleic acids from immune surveillance [47]. In the context of coronaviruses, a fine-tuned host lipid profile is essential to achieve optimal viral replication [48]. In addition to sterol metabolism, the ACE2 and TMPRSS2 co-expressing trophectodermal cells are enriched for genes involved in herpes simplex viral infection, glycan modifications, and peroxisomes. Host glycans and peroxisomes are known to support the replication and spread of some viruses [49]. The ACE2 and TMPRSS2 co-expressing epiblast cells are enriched for genes in oxidative phosphorylation. A higher expression of genes involved in metabolic pathways including oxidative 
phosphorylation is reported in neutrophils of COVID-19 patients $[50,51]$ suggesting a possible role of mitochondrial activity in SARS-CoV-2 infection. Thus, our analyses reveal that the ACE2 and TMPRSS2 co-expressing cells of the developing blastocysts specifically are augmented for a plethora of factors that aid in viral survival and replication.

Human embryos could be potentially exposed to the hCoVs via systemic infection in vivo or during in vitro embryo manipulative procedures in patients undergoing assisted reproduction. While the zona pellucida is thought to protect the early embryos from viral infections, exposure of zona-intact embryos to the Zika virus compromises their development [52, 53]. Further, in a proportion of embryos that were exposed to Zika viruses at preimplantation stages, the resulting fetuses had altered brain development [52]. These results indicate that the zona pellucida may not always protect the embryos from viral infection. While similar information for $\mathrm{hCoVs}$ is not yet available, considering our results that show that the preimplantation embryos have an abundance of genes required for viral endocytosis and infectivity, it is plausible that if the hCoVs cross the zona barrier, they may be embryo-toxic and may have long-term sequelae. Indeed, human embryos exposed to pseudotyped SARS-CoVs have compromised development, cell fragmentation, and even embryonic demise [18]. Thus, clinicians and patients seeking fertility options via in vitro fertilization must be aware of the potential negative impact of hCoVs on early developing embryos.

Overall, this study provides insight into the permissiveness of developing human embryos for multiple hCoVs and suggests that the morula and blastocyst stage embryos are most likely to get infected (Fig. 6). While this is the first in-depth survey of pan-coronavirus entry and infectivity factors in developing human embryos, it is limited by the constraints of scRNAseq. These include under-representation of rare cell types, isolation biases, and statistical cut-offs. Furthermore, RNA expression levels do not always accurately reflect protein abundance; therefore, our observations must be corroborated for protein expression in situ. Additionally, the expression of these factors may be modulated by coronaviruses themselves, resulting in completely diverse consequences. Nevertheless, our study provides valuable baseline data which will be an important resource for clinics performing in vitro fertilization procedures and to develop evidence-based guidelines for patient management and counseling during viral pandemics.

Supplementary Information The online version contains supplementary material available at https://doi.org/10.1007/s10815-021-02192-3.

Acknowledgements We express our gratitude to the Director (ICMRNIRRH) Dr. Smita Mahale for constant guidance and encouragement. The following publicly available datasets were used in this study (E-
MTAB-3929 and Stirparo et al 2018) Supplementary Table 8 and we acknowledge the authors for making them available for research use. DM lab is funded by grants from Indian Council of Medical Research (ICMR), Govt. of India. SC is thankful to the Department of Health Research (DHR), Govt. of India for the Young Scientist fellowship. KC is thankful for the Nehru-Fulbright Scholarship. AH and NS are thankful to ICMR-RA and ICMR-SRF respectively. RS is thankful to DST-Inspire fellowship, AM and DS are thankful to UGC for research fellowship. NA and $\mathrm{AB}$ are thankful to DST-SERB project fellowship. The manuscript bears the NIRRH ID RA/894/04-2020. This manuscript is released as a pre-print at https://arxiv.org/ arXiv:2004.04935.

Author contribution DM conceived the study and analyzed the results. $\mathrm{SC}, \mathrm{KC}$ and DS took the lead role, executed the study, and analyzed the data. AS, AH, RS, and AM carried out the literature survey and collected the information. NS, AB, DS, and NA helped in data assembly, analysis, and manuscript preparation. $\mathrm{AB}, \mathrm{DS}$, and $\mathrm{KC}$ prepared the figures. All the authors agreed to the final version of the manuscript.

\section{Declarations}

Conflict of interest The authors declare no competing interests.

\section{References}

1. Cui J, Li F, Shi ZL. Origin and evolution of pathogenic coronaviruses. Nat Rev Microbiol. Nature Publishing Group; 2019 [cited 2021 Mar 4]. p. 181-92. Available from: www. nature.com/nrmicro.

2. Di Mascio D, Khalil A, Saccone G, Rizzo G, Buca D, Liberati M, et al. Outcome of coronavirus spectrum infections (SARS, MERS, COVID-19) during pregnancy: a systematic review and meta-analysis. Am J Obstet Gynecol MFM. NLM (Medline); 2020 [cited 2021 Mar 6];2:100-7. Available from: https://pubmed.ncbi.nlm. nih.gov/32292902/.

3. Jafari M, Pormohammad A, Sheikh Neshin SA, Ghorbani S, Bose $\mathrm{D}$, Alimohammadi S, et al. Clinical characteristics and outcomes of pregnant women with COVID-19 and comparison with control patients: a systematic review and meta-analysis. Rev Med Virol. John Wiley and Sons Ltd; 2021 [cited 2021 Mar 6]. Available from: https://pubmed.ncbi.nlm.nih.gov/33387448/.

4. Lokken EM, Huebner EM, Taylor GG, Hendrickson S, Vanderhoeven J, Kachikis A, Coler B, Walker CL, Sheng JS, alHaddad BJS, McCartney SA, Kretzer NM, Resnick R, Barnhart N, Schulte V, Bergam B, Ma KK, Albright C, Larios V, Kelley L, Larios V, Emhoff S, Rah J, Retzlaff K, Thomas C, Paek BW, Hsu RJ, Erickson A, Chang A, Mitchell T, Hwang JK, Erickson S, Delaney S, Archabald K, Kline CR, LaCourse SM, Adams Waldorf KM. Disease severity, pregnancy outcomes and maternal deaths among pregnant patients with SARS-CoV-2 infection in Washington State. Am J Obstet Gynecol. Elsevier BV; 2021 [cited 2021 Mar 6];0. Available from: https://doi.org/10.1016/j.ajog. 2020.12 .1221$.

5. Gajbhiye R, Modi D, Mahale S. Pregnancy outcomes, newborn complications and maternal-fetal transmission of SARS-CoV-2 in women with COVID-19: a systematic review. medRxiv. Cold Spring Harbor Laboratory Press. 2020;2020(04):11.20062356.

6. Mahajan NN, Ansari M, Gaikwad C, Jadhav P, Tirkey D, Pophalkar MP, et al. Impact of SARS-CoV-2 on multiple gestation pregnancy. Int J Gynecol Obstet. John Wiley and Sons Ltd; 2021 [cited 2021 Mar 6];152:220-5. Available from: https://pubmed. ncbi.nlm.nih.gov/33259652/. 
7. Seethy AA, Singh S, Mukherjee I, Pethusamy K, Purkayastha K, Sharma JB, et al. Potential SARS-CoV-2 interactions with proteins involved in trophoblast functions - an in-silico study. Placenta. W.B. Saunders Ltd; 2021 [cited 2021 Mar 6];103:141-51. Available from: https://pubmed.ncbi.nlm.nih.gov/33126048/.

8. Lu-Culligan A, Chavan AR, Vijayakumar P, Irshaid L, Courchaine $\mathrm{EM}$, Milano KM, et al. SARS-CoV-2 infection in pregnancy is associated with robust inflammatory response at the maternal-fetal interface. medRxiv Prepr Serv Heal Sci. medRxiv; 2021 [cited 2021 Mar 6]; Available from: http://www.ncbi.nlm.nih.gov/ pubmed/33532791.

9. Ashary N, Bhide A, Chakraborty P, Colaco S, Mishra A, Chhabria $\mathrm{K}$, et al. Single-Cell RNA-seq identifies cell subsets in human placenta that highly expresses factors driving pathogenesis of SARSCoV-2. Front Cell Dev Biol. Frontiers; 2020 [cited 2020 Aug 21];8: 783. Available from: https://www.frontiersin.org/article/10.3389/ fcell.2020.00783/full.

10. Shende P, Gaikwad P, Gandhewar M, Ukey P, Bhide A, Patel V, et al. Persistence of SARS-CoV-2 in the first trimester placenta leading to transplacental transmission and fetal demise from an asymptomatic mother. Hum Reprod. Oxford University Press (OUP); 2021 [cited 2021 Mar 6];36:899-906. Available from: https://pubmed.ncbi.nlm.nih.gov/33346816/.

11. Vivanti AJ, Vauloup-Fellous C, Prevot S, Zupan V, Suffee C, Do Cao J, et al. Transplacental transmission of SARS-CoV-2 infection. Nat Commun. Nature Research; 2020 [cited 2020 Aug 15];11:1-7. Available from: https://doi.org/10.1038/s41467-020-17436-6.

12. Hosier H, Farhadian SF, Morotti RA, Deshmukh U, Lu-Culligan A, Campbell KH, et al. SARS-CoV-2 infection of the placenta. J Clin Invest. American Society for Clinical Investigation; 2020 [cited 2021 Mar 6];130:4947-53. Available from: https://pubmed.ncbi. nlm.nih.gov/32573498/.

13. Essahib W, Verheyen G, Tournaye H, Van de Velde H. SARSCoV-2 host receptors ACE2 and CD147 (BSG) are present on human oocytes and blastocysts. J Assist Reprod Genet. Springer; 2020 [cited 2021 Mar 6];37:2657-60. Available from: https:// pubmed.ncbi.nlm.nih.gov/32959144/.

14. Chen W, Yuan P, Yang M, Yan Z, Kong S, Yan J, et al. SARSCoV-2 entry factors: ACE2 and TMPRSS2 are expressed in periimplantation embryos and the maternal-fetal interface. Engineering. Elsevier Ltd. 2020;6:1162-9.

15. Rajput SK, Logsdon DM, Kile B, Engelhorn HJ, Goheen B, Khan $\mathrm{S}$, et al. Human eggs, zygotes, and embryos express the receptor ACE2 and protease TMPRSS2 protein necessary for SARS-CoV-2 infection. F\&S Sci. Elsevier BV; 2020 [cited 2021 Mar 6];2. Available from: https://pubmed.ncbi.nlm.nih.gov/33521687/.

16. Weatherbee BAT, Glover DM, Zernicka-Goetz M. Expression of SARS-CoV-2 receptor ACE2 and the protease TMPRSS2 suggests susceptibility of the human embryo in the first trimester. Open Biol. Royal Society Publishing; 2020 [cited 2021 Mar 6];10. Available from: https://pubmed.ncbi.nlm.nih.gov/32750256/.

17. Colaco S, Chhabria K, Singh D, Bhide A, Singh N, Singh A, et al. A single-cell RNA expression map of coronavirus receptors and associated factors in developing human embryos. arXiv. arXiv; 2020 [cited 2021 Mar 6]; arXiv:2004.04935v2. Available from: http://arxiv.org/abs/2004.04935.

18. Montano M, Victor AR, Griffin DK, Duong T, Bolduc N, Farmer A, et al. Human pre-implantation embryos are permissive to SARSCoV-2 entry. bioRxiv. Cold Spring Harbor Laboratory; 2021 [cited 2021 Mar 6]. p. 2021.01.21.427501. Available from: https://doi. org/10.1101/2021.01.21.427501.

19. Millet JK, Jaimes JA, Whittaker GR. Molecular diversity of coronavirus host cell entry receptors. FEMS Microbiol Rev. Oxford University Press (OUP); 2020 [cited 2021 Mar 6];057:1-16. Available from: https://academic.oup.com/femsre/advance-article/ doi/10.1093/femsre/fuaa057/5942658.
20. Hoffmann M, Kleine-Weber H, Schroeder S, Krüger N, Herrler T, Erichsen S, et al. SARS-CoV-2 cell entry depends on ACE2 and TMPRSS2 and is blocked by a clinically proven protease inhibitor. Cell. 2020:1-10.

21. Gadanec LK, McSweeney KR, Qaradakhi T, Ali B, Zulli A, Apostolopoulos V. Can SARS-CoV-2 virus use multiple receptors to enter host cells?. Int J Mol Sci. MDPI AG; 2021 [cited 2021 Mar 6]. p. 1-35. Available from: https://pubmed.ncbi.nlm.nih.gov/ 33498183/.

22. Daly JL, Simonetti B, Klein K, Chen KE, Williamson MK, AntónPlágaro C, et al. Neuropilin-1 is a host factor for SARS-CoV-2 infection. Science (80- ). American Association for the Advancement of Science; 2020 [cited 2021 Mar 6];370:861-5. Available from: https://pubmed.ncbi.nlm.nih.gov/33082294/.

23. Cantuti-Castelvetri L, Ojha R, Pedro LD, Djannatian M, Franz J, Kuivanen S, et al. Neuropilin-1 facilitates SARS-CoV-2 cell entry and infectivity. Science (80- ). American Association for the Advancement of Science; 2020 [cited 2021 Mar 6];370. Available from: https://pubmed.ncbi.nlm.nih.gov/33082293/.

24. Wang K, Chen W, Zhang Z, Deng Y, Lian JQ, Du P, et al. CD147spike protein is a novel route for SARS-CoV-2 infection to host cells. Signal Transduct Target Ther. Springer Nature; 2020 [cited 2021 Mar 6];5. Available from: https://pubmed.ncbi.nlm.nih.gov/ $33277466 /$.

25. Gordon DE, Hiatt J, Bouhaddou M, Rezelj V V., Ulferts S, Braberg $\mathrm{H}$, et al. Comparative host-coronavirus protein interaction networks reveal pan-viral disease mechanisms. Science (80- ). American Association for the Advancement of Science; 2020 [cited 2021 Mar 6];370. Available from: https://pubmed.ncbi.nlm.nih.gov/ $33060197 /$.

26. Kaur U, Chakrabarti SS, Ojha B, Pathak BK, Singh A, Saso L, et al. Targeting host cell proteases to prevent SARS-CoV-2 invasion. Curr Drug Targets. Bentham Science Publishers Ltd.; 2020 [cited 2021 Mar 6];21. Available from: https://pubmed.ncbi.nlm.nih.gov/ $32972339 /$.

27. Zang R, Castro MFG, McCune BT, Zeng Q, Rothlauf PW, Sonnek NM, et al. TMPRSS2 and TMPRSS4 promote SARS-CoV-2 infection of human small intestinal enterocytes. Sci Immunol. American Association for the Advancement of Science; 2020 [cited 2021 Mar 6];5. Available from: https://pubmed.ncbi.nlm.nih.gov/32404436/.

28. Millet JK, Whittaker GR. Host cell proteases: critical determinants of coronavirus tropism and pathogenesis. Virus Res. Elsevier; 2015 [cited 2021 Mar 6];202:120-34. Available from: https://pubmed. ncbi.nlm.nih.gov/25445340/.

29. Pišlar A, Mitrovic A, Sabotič J, Fonovic UP, Nanut MP, Jakoš T, et al. The role of cysteine peptidases in coronavirus cell entry and replication: the therapeutic potential of cathepsin inhibitors. PLoS Pathog. Public Library of Science; 2020 [cited 2021 Mar 6]. p. e1009013. Available from: https://doi.org/10.1371/journal.ppat. 1009013.g001.

30. Zhao M-M, Yang W-L, Yang F-Y, Zhang L, Huang W-J, Hou W, et al. Cathepsin L plays a key role in SARS-CoV-2 infection in humans and humanized mice and is a promising target for new drug development. Signal Transduct Target Ther. Nature Publishing Group; 2021 [cited 2021 Apr 6];6:134. Available from: http:// www.nature.com/articles/s41392-021-00558-8.

31. Cheng YW, Chao TL, Li CL, Chiu MF, Kao HC, Wang SH, et al. Furin inhibitors block SARS-CoV-2 spike protein cleavage to suppress virus production and cytopathic effects. Cell Rep. Elsevier B.V.; 2020 [cited 2021 Apr 6];33:108254. Available from: https:// pubmed.ncbi.nlm.nih.gov/33007239/.

32. Ahmed I, Akram Z, Iqbal HMN, Munn AL. The regulation of endosomal sorting complex required for transport and accessory proteins in multivesicular body sorting and enveloped viral budding — an overview. Int J Biol Macromol. 2019;127:1-11. 
33. Gordon DE, Jang GM, Bouhaddou M, Xu J, Obernier K, White $\mathrm{KM}$, et al. A SARS-CoV-2 protein interaction map reveals targets for drug repurposing. Nature. Nature Publishing Group; 2020 [cited 2020 May 6];1-13. Available from: http://www.nature.com/ articles/s41586-020-2286-9.

34. Stirparo GG, Boroviak T, Guo G, Nichols J, Smith A, Bertone P. Integrated analysis of single-cell embryo data yields a unified transcriptome signature for the human pre-implantation epiblast. Dev. 2018;145.

35. Petropoulos S, Edsgärd D, Reinius B, Deng Q, Panula SP, Codeluppi S, et al. Single-cell RNA-Seq reveals lineage and X chromosome dynamics in human preimplantation embryos. Cell. Cell Press. 2016;165:1012-26.

36. Yan L, Yang M, Guo H, Yang L, Wu J, Li R, et al. Single-cell RNA-Seq profiling of human preimplantation embryos and embryonic stem cells. Nat Struct Mol Biol. Nature Publishing Group. 2013;20:1131-9.

37. Blakeley P, Fogarty NME, Del Valle I, Wamaitha SE, Hu TX, Elder K, et al. Defining the three cell lineages of the human blastocyst by single-cell RNA-seq. Dev. Company of Biologists Ltd. 2015;142:3151-65.

38. de Wilde AH, Snijder EJ, Kikkert M, van Hemert MJ. Host factors in coronavirus replication. Curr Top Microbiol Immunol. Springer Verlag. 2018:1-42. Available from: https://pubmed.ncbi.nlm.nih. gov/28643204/

39. Bharti S, 1\# N, Chugh P, Choudhury A, Bhatnagar S, Sengupta A, et al. Multi-parametric disease dynamics study and analysis of the COVID-19 epidemic and implementation of population-wide intrusions: the Indian perspective. [cited $2020 \mathrm{Jul} 12$ ]; Available from: https://doi.org/10.1101/2020.06.02.20120360.

40. Waghmare R, Gajbhiye R, Mahajan N, Modi D, Mukherjee S, Mahale S. Universal screening identifies asymptomatic carriers of SARS-CoV-2 among pregnant women in India. Eur J Obstet Gynecol Reprod Biol. Elsevier BV; 2020 [cited 2020 Nov 2]; Available from: https://www.ncbi.nlm.nih.gov/pmc/articles/ PMC7510530/.

41. Choi H, Chatterjee P, Coppin JD, Martel JA, Hwang M, Jinadatha $\mathrm{C}$, et al. Current understanding of the surface contamination and contact transmission of SARS-CoV-2 in healthcare settings. Environ Chem Lett. Springer Science and Business Media LLC; 2021 [cited 2021 Mar 6];1:1. Available from: https://pubmed.ncbi. nlm.nih.gov/33613145/.

42. Scarica C, Parmegiani L, Rienzi L, Anastasi A, Cimadomo D, Klinger FG, et al. SARS-CoV-2 persistence at subzero temperatures. J. Assist. Reprod. Genet. Springer; 2021 [cited 2021 Mar 6]. Available from: https://pubmed.ncbi.nlm.nih.gov/33544317/.

43. Maggiulli R, Giancani A, Fabozzi G, Dovere L, Tacconi L, Amendola MG, et al. Assessment and management of the risk of SARS-CoV-2 infection in an IVF laboratory. Reprod Biomed Online. Elsevier Ltd; 2020 [cited 2021 Mar 6];41:385-94. Available from: https://pubmed.ncbi.nlm.nih.gov/32693991/.

44. Simopoulou M, Sfakianoudis K, Giannelou P, Rapani A, Siristatidis C, Bakas P, et al. Navigating assisted reproduction treatment in the time of COVID-19: concerns and considerations. J. Assist. Reprod. Genet. Springer; 2020 [cited 2021 Mar 6]. p. 2663-8. Available from: https://pubmed.ncbi.nlm.nih.gov/ 32939662/.

45. Jirge PR, Patwardhan S, Jirge S, Bhomkar D, Chougule S, Salpekar $\mathrm{A}$, et al. Resuming assisted reproduction services during COVID19 pandemic: an initial Indian experience. J Hum Reprod Sci. Wolters Kluwer Medknow Publications; 2020 [cited 2021 Mar 6];13:323-32. Available from: https://pubmed.ncbi.nlm.nih.gov/ $33627983 /$.

46. Wang H, Yang P, Liu K, Guo F, Zhang Y, Zhang G, et al. SARS coronavirus entry into host cells through a novel clathrin- and caveolae-independent endocytic pathway. Cell Res. 2008;18:290 301 .

47. Mayer KA, Stöck1 J, Zlabinger GJ, Gualdoni GA. Hijacking the supplies: metabolism as a novel facet of virus-host interaction. Front. Immunol. Frontiers Media S.A.; 2019;10:1533. Available from: https://pubmed.ncbi.nlm.nih.gov/31333664/.

48. Yan B, Chu H, Yang D, Sze KH, Lai PM, Yuan S, et al. Characterization of the lipidomic profile of human coronavirusinfected cells: implications for lipid metabolism remodeling upon coronavirus replication. Viruses. MDPI AG; 2019 [cited 2020 Jul 22];11. Available from: https://pubmed.ncbi.nlm.nih.gov/ 30654597/.

49. Lazarow PB. Viruses exploiting peroxisomes. Curr Opin Microbiol. 2011;14(4):458-69. Available from: https://doi.org/10. 1016/j.mib.2011.07.009.

50. Gardinassi LG, Souza COS, Sales-Campos H, Fonseca SG. Immune and metabolic signatures of COVID-19 revealed by transcriptomics data reuse. Front Immunol. Frontiers Media SA. 2020;11:1636. Available from: https://pubmed.ncbi.nlm.nih.gov/ 32670298/.

51. Singh K, Chen Y-C, Judy JT, Seifuddin F, Tunc I, Pirooznia M. Network analysis and transcriptome profiling identify autophagic and mitochondrial dysfunctions in SARS-CoV-2 infection. bioRxiv. Cold Spring Harbor Laboratory. 2020;2020(05): 13.092536 .

52. Tan L, Lacko LA, Zhou T, Tomoiaga D, Hurtado R, Zhang T, et al. Pre- and peri-implantation Zika virus infection impairs fetal development by targeting trophectoderm cells. Nat Commun. Nature Publishing Group; 2019 [cited 2021 Mar 6];10. Available from: https://pubmed.ncbi.nlm.nih.gov/31519912/.

53. Block LN, Aliota MT, Friedrich TC, Schotzko ML, Mean KD, Wiepz GJ, et al. Embryotoxic impact of Zika virus in a rhesus macaque in vitro implantation model. Biol Reprod. Oxford University Press; 2020 [cited 2021 Mar 6];102:806-16. Available from: https://pubmed.ncbi.nlm.nih.gov/31901091/.

Publisher's note Springer Nature remains neutral with regard to jurisdictional claims in published maps and institutional affiliations. 